\section{Military Technical College}

Kobry El-Kobbah, Cairo, Egypt

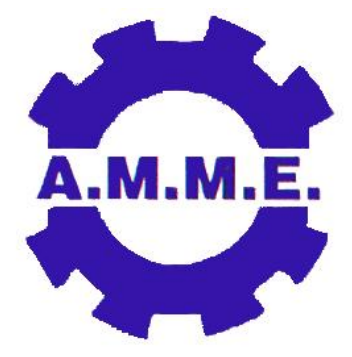

$14^{\text {th }}$ International Conference on

Applied Mechanics and Mechanical Engineering.

\title{
COEFFICIENT OF SENSITIVENESS TO A REGISTERED CROSS- SYMMETRIC CRACK AT STABILITY OF A SLENDER PRISMATIC COLUMN
}

By

\author{
Varvara VESELINOVA-GUTEVA*
}

\begin{abstract}
:
Subject of research in the publication is a steel column with a square cross section with registered not-developing, end, cross-symmetric crack with different extent of penetration and different location longwise the column, which is loaded with, concentrated centrally applied force in the free, border cross section. Determined are the values of the critical force through a direct method of stability analysis of one-dimensional tasks. The area of the column that contains the cross section with a registered crack is being shaped through a torsion spring, as the elements of the matrix for its stiffness are determined through the theorem of Castiglano and the methods of the linear fracture mechanics. The impact of the location and the extent of the penetration of a registered crack on the value of the critical force has been proved. A coefficient of sensitiveness has been entered to the registered cross-symmetric crack for the researched steel column through which the complex impact of the location and the extent of penetration on the value of the critical force is calculated.
\end{abstract}

Keywords: Column, crack, finite elements method, stability. 


\section{* TECHNICAL UNIVERSITY -VARNA 9010 BULGARIA}

\section{Introduction:}

The main task in the theory of stability of elastic systems is to develop adequate methods for accurate determination of critical parameters for which in order to exist there is a need to have such a numerical value of the growing load attached to the elastic elements at which value it is possible qualitatively new balanced shape. This task is the subject of research carried out by Timoshenko SP and others [1961]; Gerard G. and others [1971]; Bazant Z.P. and others [1991, 1997]; Fan S.C. and others [2001, 2003]; Kishen J.M.C. and others [2004]; Kisa M. and others [2000a., 2000b., 2000c., 2004]; Dimarogonas AD and others [1987]; Papadopoulos S.A. and others [1988, 1992, 2004]; Lee H.P. [1992]; Shen M.H.H. and others [1990]; Kikidis M.L. and others [1992]; Abraham O.N.L. and others [1994]; Takahashi I. [1998, 1999]; Zheng D.Y. and others [2001a., 2001b., 2003]; Khiem N.T. and others [2001]; Subrahmanyam K.B. and others [1997]; Li Q.S. [2002, 2003]; Ruotolo R. and others [2004]; Bilello C. and others [2004] and Ozen M. [2005]. In some of the publications, the final results of the critical parameters are directly summarized, and there are also developed and refined mathematical procedures for the analytical solution for systems with a finite number of extents of looseness and for systems with an infinite number of extents of looseness by applying the direct method of solving equations of indifferent equilibrium or by establishing power criterion for indifferent equilibrium.

A critical analysis of the variations of the static method and the varieties of power method for determining the own numbers and own functions of the differential equations have been prepared taking into consideration the recorded deviations from the geometric shape of the elastic elements of the scheme of loading of the elastic elements, of the prerequisites in place and hypotheses of a perfect homogeneity of the material for ideal elasticity of the material and for linear relationship between stress and deformation. In another part of the publications there has been analysed the impact of registered disintegrations from the type - symmetrical cross surface cracks on vibration state of the elastic elements as the effect of the recorded cracks is recognized as a change of stiffness in bending in a plane perpendicular to the plane 
of the crack development. Elastic beams were tested with cross-registered end unilateral or bilateral symmetrical cracks. Differential equations are summarized for the free cross oscillations under the variation principle of the Hu-Washizu-Barr by introducing a model of the local concentrated susceptibility of the crack through spring-loaded joint (swivel) which stiffness is determined by the coefficients of stress intensity in the various schemes of distribution of crack according to linear fracture mechanics [Dimarogonas $A D$ and Papadopoulos C.A.].

The corresponding border problems are formulated the solutions of which satisfy the system of partial differential equations expressing the conditions for dynamic equilibrium, the conditions of compatibility of strains and tensions within the surveyed area, and at the borders area that satisfy the prescribed border conditions reflecting the manner of loading and the method of attachment. The practical solution is performed by the finite elements method as the area containing the recorded crack is represented with variable typical parameters of the cross-sections [Lee HP; Shen MHH and C. Pierre]. In the studies of I. Takahashi a procedure for analysing the vibration state of a shaft with a recorded cross symmetric end crack is suggested to be adapted to the task of sustainability of the elastic element. For that reason the power criterion is formulated for indifferent equilibrium for a shaft, provided that it is loaded with unevenly distributed axial load unlike the scheme of S.P. Timoshenko. This parallel approach to the research presented in the publications of D.Y. Zheng and S. C. Fan of elastic beams with recorded cracks and different configuration in cross-sections, which presents the results of experimental studies on local susceptibility coefficients provided that the registered crack with varying extents of penetration is completely open. The final results for the critical force are summarized for a column with a registered crack in various schemes of attachment of border sections.

The purpose of this work is to define the critical force for a steel column with square crosssection with registered cross crack in a different location lengthwise of the column with different extents of penetration and under different schemes of attachment of the border sections through a direct method for analysing the stability of one-dimensional tasks.

Studies have been performed in a plane perpendicular to the plane of development of the registered crack which is characterized by minimum values for the stiffness of the column in particular cross bending. For the practical tasks fulfilment that ensures the implementation of the formulated purpose a established synthesized one-dimensional computer model of the column in the FRAME programming environment is used. In the group of compulsory input data required by which there are described the physical and mechanical characteristics of the research material for the column include as follows: modulus of elasticity of the first kind $E=$ $2,0.10^{5}[\mathrm{MPa}]$ and Poisson ratio $\mu=0,250$.

\section{Mathematical model - preparing the characteristic equation for determining the critical parameter :}

Slender prismatic steel column with length $L_{0}$ and square cross section with measures $b_{0} \times$ $\mathrm{h}_{0}$, in which a non progressing cross crack has been registered with depth of penetration $\ell$, contour surfaces of the crack $F_{\ell}$ and position coordinate $x_{\ell}$ determining the location of the crack towards the right border section of the column is shown at figure $1 .-a$. The column is 
divided into two force sections of the intermediate border section that is defined by the plane of the registered crack progress - figure 1. -a. As a result of this, the global geometrical non linear system is divided into two geometrical linear subsystems that are connected through a torsion progress - figure 1. -b. As a result of this, the global geometrical non linear system is divided into two geometrical linear subsystems that are connected through a torsion spring which stiffness is determined by the local stiffness of the column upon the presence of a particular registered crack. Each of the geometrical linear subsystems is divided into a finite number of elements with two meetings and three stages of looseness - figure 1. - c. Each element is reviewed as a bilaterally blocked rod with length $L_{\text {ел }}$ and rectilinear geometrical axis that has been loaded with two directly opposite axial pressure forces $P$.

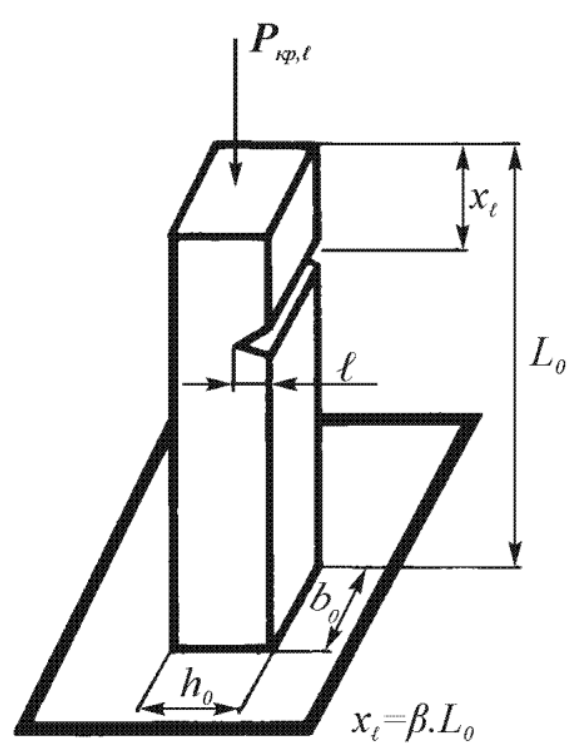

scheme a.

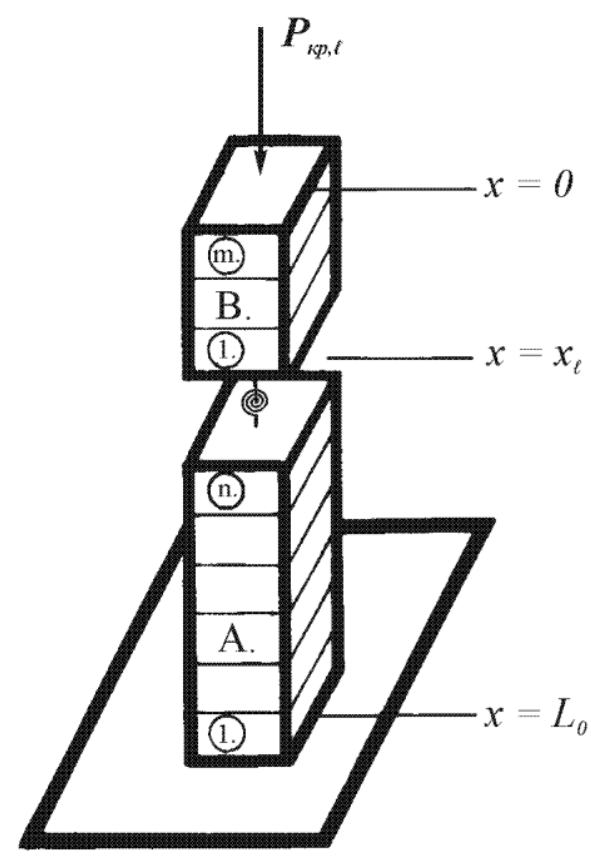

scheme $b$.

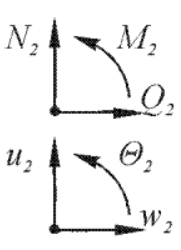

meeting 2

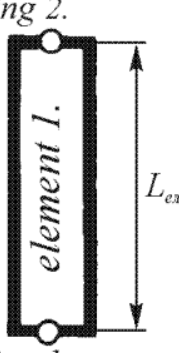

meeting 1 .

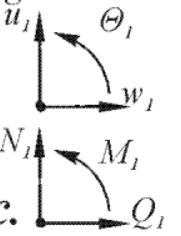

Figure (1): Slender prismatic column with registered non developing cross unilateral symmetric plane crack

In the present work, the static analysis of the reviewed column is performed through the matrix method of transfers for frame constructions that essentially is a deformation method and is very appropriate in reporting the effect of the normal internal exertions on the general state of pressure i.e. in solving physically non linear problems in order to determine the critical external load. A differential equation is drawn up of the axis of the deformed element. A homogeneous linear differential equation is summarized as one of fourth line with constant coefficients and the general integral is presented. There are determined the integration constants of the border conditions and the reactions of the meetings from the single summarized transfers. The matrix of stiffness is formed as to report the effect of the nonlinearity between the external load and the internal exertions: 
Proceeding of the $14^{\text {th }}$ AMME Conference, 25 -27 May 2010

$$
\left[k_{\text {ел. }}\right]=\left[\begin{array}{cccccc}
E . F_{0} \cdot L_{\text {ел. }}^{-1} & 0 & 0 & -E . F_{0} \cdot L_{\text {eл. }}^{-1} & 0 & 0 \\
0 & R_{1} & R_{2} & 0 & -R_{1} & R_{2} \\
0 & R_{2} & R_{4} & 0 & -R_{2} & R_{3} \\
-E . F_{0} \cdot L_{\text {eл. }}^{-1} & 0 & 0 & E . F_{0} \cdot L_{\text {eл. }}^{-1} & 0 & 0 \\
0 & -R_{1} & -R_{2} & 0 & R_{1} & -R_{2} \\
0 & R_{2} & R_{3} & 0 & -R_{2} & R_{4}
\end{array}\right]_{(6 \times 6)}
$$

where:

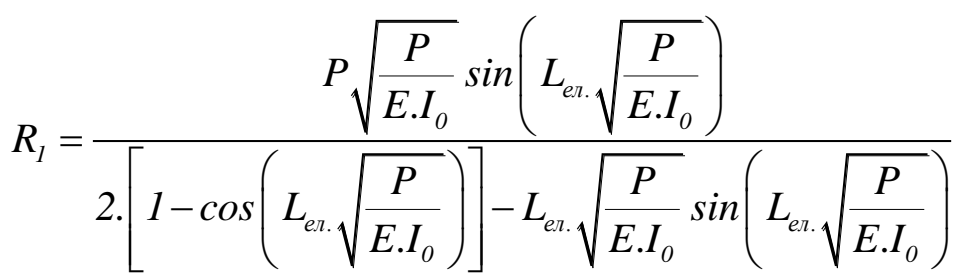

$$
\begin{aligned}
& R_{2}=\frac{P\left[1-\cos \left(L_{\text {ел. }} \sqrt{\frac{P}{E . I_{0}}}\right)\right]}{2 .\left[1-\cos \left(L_{\text {ел. }} \sqrt{\frac{P}{E . I_{0}}}\right)\right]-L_{\text {ел. }} \sqrt{\frac{P}{E . I_{0}}} \sin \left(L_{\text {ел. } \sqrt{\frac{P}{E . I_{0}}}}\right)}
\end{aligned}
$$

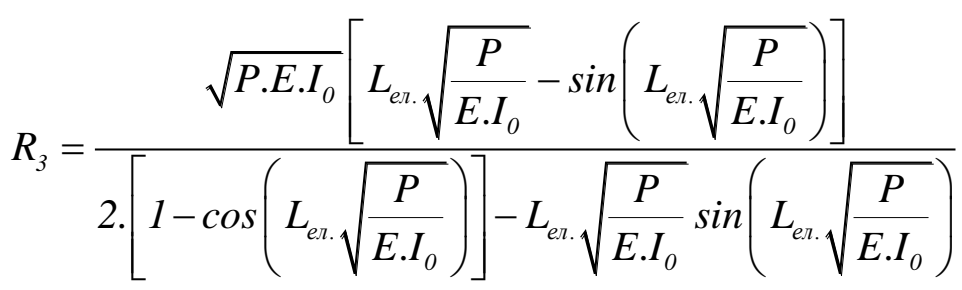

$$
\begin{aligned}
& R_{4}=\frac{\sqrt{P . E . I_{0}}\left[\sin \left(L_{\text {ел. }} \sqrt{\frac{P}{E . I_{0}}}\right)-L_{\text {ел. }} \sqrt{\frac{P}{E . I_{0}}} \cos \left(L_{\text {ел. }} \sqrt{\frac{P}{E . I_{0}}}\right)\right]}{2 .\left[1-\cos \left(L_{\text {ел. }} \sqrt{\frac{P}{E . I_{0}}}\right)\right]-L_{\text {ел. }} \sqrt{\frac{P}{E . I_{0}}} \sin \left(L_{\text {ел. }} \sqrt{\frac{P}{E . I_{0}}}\right)}
\end{aligned}
$$

The suggested method of calculating the stiffness of the matrix is called a direct method and is an accurate method, but it has a major defect - at $P=0$ for the components of the matrix of stiffness, the indefiniteness 0:0 is obtained. This defect is eliminated in the indirect method of consecutive accessions where the matrix of stiffness is given as a sum of two matrices: 


$$
\left[k_{\text {ел. }}\right]=\left[k_{\text {ел. }}\right]^{*}+\left[k_{\text {ел. }}\right]^{* *}
$$

where: $\left[k_{e r}\right]^{*}$ is the matrix of stiffness that does not report the non linearity between the external load and the internal exertions and $\left[k_{\text {en. }}\right]^{* *}$ is the matrix of stiffness which components are the additionally bending moments and their respective cross section forces caused by the pressure force $\boldsymbol{P}$ and are of the type:

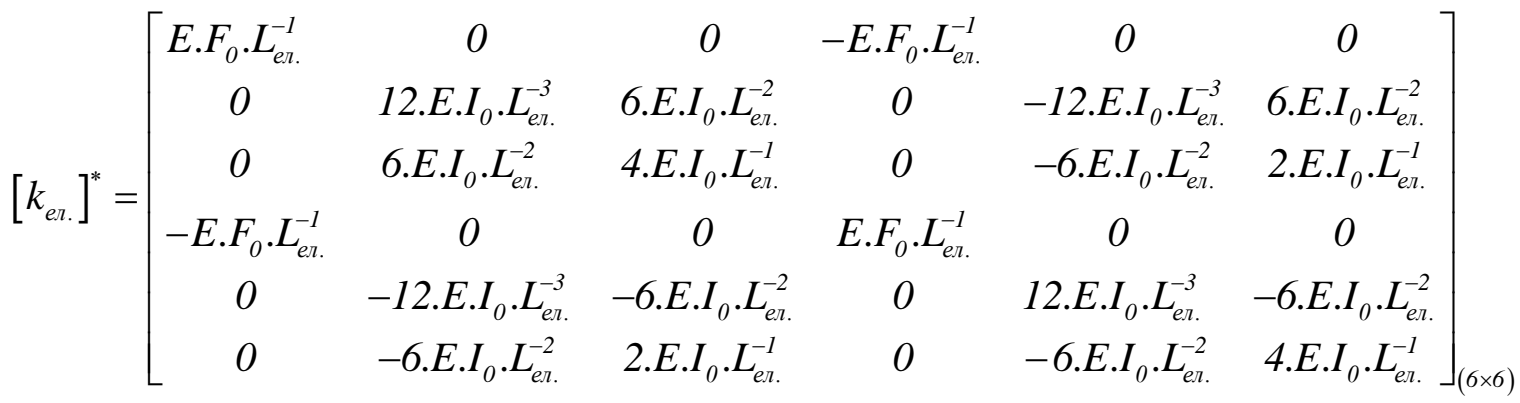

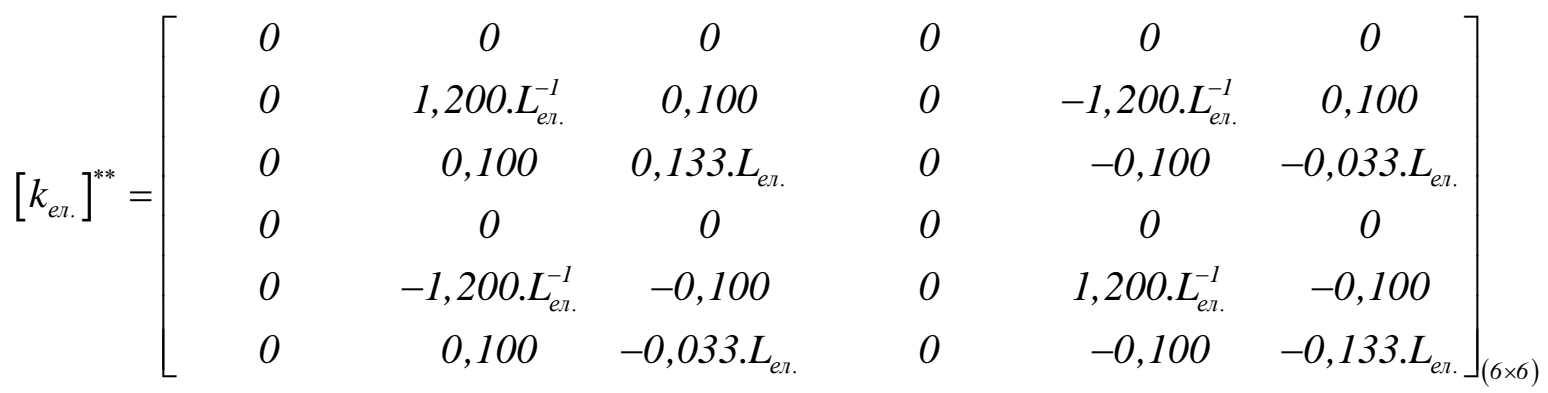

Pursuant to the Sen-Venant principle, the effect of registered crack results on the summarized transfers of the meetings between the elements that specify the exerted and the deformed state around a point of the reviewed column in an area sufficiently close to the plane of crack spreading. In the scientific works of Cherepanov G..P. and of Rhyse D.R upon carrying out researches of the elastic-plastic construction materials applies the deformation theory of the plasticity. In this case upon reviewing the stage of active deformation, the elastic-plastic materials are reviewed as physically non linear elastic materials that give the opportunity to use the properly developed mathematical mechanism of non linear elastic mechanics, but no unloadings are admitted. Therefore the connection between the elements of the tensor-pressure and the tensor-deformation in elastic-plastic material is preserved as it is in the non linear elastic material but only to the moment of unloading. That very condition is very important upon entering and determining the invariant characteristic J-integral, through which the additional energy that must come in the climax of the crack is interpreted in order to increase with one, the area of its contour surface upon the relevant value of the internal exertions i.e.: 


$$
J=\frac{\partial U\left(N_{i}, Q_{i}, M_{i}, N_{j}, Q_{j}, M_{j}, F_{\ell}\right)}{\partial F_{\ell}}=\frac{\partial U\left(P_{i}, P_{j}, F_{\ell}\right)}{\partial F_{\ell}}
$$

Applying the Castigliano theorem there are determined the additional summarized transfers of the meetings to the element consisting the registered crack $\left\{\bar{\delta}_{i}\right\}$ and $\left\{\overline{\delta_{j}}\right\}$ on the direction of the summarized force factors $\left\{P_{i}\right\}$ and $\left\{P_{j}\right\}$ through the dependencies:

$$
\begin{aligned}
& \overline{\delta_{i}}=\frac{\partial U\left(P_{i}, P_{j}, F_{\ell}\right)}{\partial P_{i}}=\frac{\partial}{\partial P_{i}} \int_{\left(F_{\ell}\right)} J\left(P_{i}, P_{j}, F_{\ell}\right) d F_{\ell} \\
& \overline{\delta_{j}}=\frac{\partial U\left(P_{i}, P_{j}, F_{\ell}\right)}{\partial P_{j}}=\frac{\partial}{\partial P_{j}} \int_{\left(F_{\ell}\right)} J\left(P_{i}, P_{j}, F_{\ell}\right) d F_{\ell}
\end{aligned}
$$

The coefficients of susceptibility of the meetings to the element consisting the registered crack are functions of the parameters determining the crack and the coefficient of intensity of the tensions and are determined through the dependencies:

$$
\begin{gathered}
c_{i s}=\frac{\partial \overline{\delta_{i}}}{\partial P_{s}}=\frac{\partial}{\partial P_{i} \cdot \partial P_{s}} \int_{\left(F_{\ell}\right)} J\left(P_{i}, P_{j}, F_{\ell}\right) \cdot d F_{\ell} \\
c_{j s}=\frac{\partial \overline{\delta_{j}}}{\partial P_{s}}=\frac{\partial}{\partial P_{j} \cdot \partial P_{s}} \int_{\left(F_{\ell}\right)} J\left(P_{i}, P_{j}, F_{\ell}\right) d F_{\ell}
\end{gathered}
$$

The matrix of susceptibility for a meeting of the element provided that the effect of the cross exertions is not considered takes the type:

$$
[C]=\left[\begin{array}{ccc}
c_{11} & 0 & c_{13} \\
0 & c_{22} & 0 \\
c_{31} & 0 & c_{33}
\end{array}\right]_{(3 \times 3)}
$$

where:

$$
\left.\begin{array}{l}
c_{11}=\frac{\partial^{2}}{\partial N_{i}^{2}} \int_{\left(F_{\ell}\right)} J\left(N_{i}, Q_{i}, M_{i}, N_{j}, Q_{j}, M_{j}, F_{\ell}\right) d F_{\ell} \\
c_{22}=\frac{\partial^{2}}{\partial Q_{i}^{2}} \int_{\left(F_{\ell}\right)} J\left(N_{i}, Q_{i}, M_{i}, N_{j}, Q_{j}, M_{j}, F_{\ell}\right) d F_{\ell} \\
c_{33}=\frac{\partial^{2}}{\partial M_{i}^{2}} \int_{\left(F_{\ell}\right)} J\left(N_{i}, Q_{i}, M_{i}, N_{j}, Q_{j}, M_{j}, F_{\ell}\right) d F_{\ell} \\
c_{13}=c_{31}=\frac{\partial^{2}}{\partial N_{i} \partial M_{i}} \int_{\left(F_{\ell}\right)} J\left(N_{i}, Q_{i}, M_{i}, N_{j}, Q_{j}, M_{j}\right) d F_{\ell}
\end{array}\right\}
$$


The reverse matrix of (10.) is a submatrix of stiffness of the element consisting the registered crack that has the type:

$$
\left[k_{\ell}\right]=\left[\begin{array}{cc}
{[C]^{-1}} & -[C]^{-1} \\
-[C]^{-1} & {[C]^{-1}}
\end{array}\right]_{(6 \times 6)}
$$

The stability analysis of the examined column with registered crack intends to determine the minimum possible value of the centrally applied pressure force that brings the column out of its stable equilibrium. That is why we will initially assume that the column has been loaded with single force $\vec{P}=1$ circular to pressure. There has been formulated a matrix of stiffness of each element that does not report the non linearity between the external load and the internal exertions $\left[\tilde{k}_{e r}\right]^{*}-(3$.$) ; the matrix of stiffness for each element which components are the$ additional bending moments and their relevant cross forces caused by a single load $\left[\tilde{k}_{e n .}\right]^{* *}$ (4.) and the matrix of stiffness for the element consisting the registered crack $\left[k_{\ell}\right]$ - (12.). Provided that the applied single pressure force is increased by $\lambda$-times due to the linearity of the static analysis, the dependencies between the respective matrices of stiffness and the vectors of the summarized meeting loads become effective:

$$
\left.\begin{array}{l}
\{P\}=\lambda\{\mid \boldsymbol{P}\} \\
{\left[k_{e l .}\right]^{*}=\left[\tilde{k}_{e r .}\right]^{*}} \\
{\left[k_{\ell}\right]=\left[\tilde{k}_{\ell}\right]} \\
{\left[k_{e l .}\right]^{* *}=\lambda \cdot\left[\tilde{k}_{e r .}\right]^{* *}}
\end{array}\right\}
$$

The general matrix of stiffness upon a particular load of the column has the type:

$$
[K]=\sum_{i, j=1}^{n, m}\left[k_{i, j}\right]=\sum_{i, j=1}^{n, m}\left[\left[k_{e n}\right]^{*}-\left[k_{\ell}\right]+\lambda \cdot\left[\tilde{k}_{e \lambda .}\right]^{* *}\right]
$$

and the system of algebraic equations for the equilibrium of the summarized reactive meeting forces with summarized external meeting load is:

$$
[K]\left\{\delta_{\Sigma}\right\}-\lambda \cdot\{P\}=0
$$

i.e.

$$
\sum_{i, j=1}^{n, m}\left[\left[k_{e n}\right]^{*}-\left[k_{\ell}\right]+\lambda \cdot\left[\tilde{k}_{e r .}\right]^{* *}\right]\left\{\delta_{\Sigma}\right\}-\lambda\{P\}=0
$$


from where the vector of the unidentified meeting transfers is summarized:

$$
\left\{\delta_{\Sigma}\right\}=\sum_{i, j=1}^{n, m}\left[\left[k_{e n}\right]^{*}-\left[k_{\ell}\right]+\lambda \cdot\left[\widetilde{k}_{e n}\right]^{* *}\right]^{-1} \cdot \lambda\{P\} .
$$

The critical force is the force upon which comes the indifferent equilibrium and the vector of the meeting transfers tends to infinity, which is possible if the following condition is met:

$$
\sum_{i, j=1}^{n, m}\left[\left[k_{e n}\right]^{*}-\left[k_{\ell}\right]+\lambda \cdot\left[\tilde{k}_{e r .}\right]^{* *}\right]=0
$$

i.e.

$$
\operatorname{det}[k(\lambda)]=0 .
$$

Equation (19.) appears to be a characteristical equation for determining the $\lambda$ parameter and the minimum possible value of the critical parameter through which the critical force is determined:

$$
P_{k p, \ell}=\lambda_{k p, \ell} . P
$$

for the examined column with registered cross section crack with a particular depth of penetration, particular location lengthwise of the column and a particular scheme of attaching the border sections of the column.

A computer programme has been developed of the described algorithm for determining the critical parameter upon stability of columns with registered cross section crack in a program environments SAGS and LAGS of the programme product FRAME by SDRS designated for static, border and dynamic analysis of constructions from beam type as both programmes are based on the matrix method of transfers.

\section{Comparative analysis of the results - conclusions:}

In this section of the present work, a profound analysis has been made of the effects of the registered cross cracks with different extent of penetration $\ell_{i}$ and different location $x_{\ell}^{i}$ in two slender prismatic columns with same geometric shape of the cross sections, same geometrical measures and made of the same construction material but upon different schemes of attachment of the border sections - figure 2. There are summarized the values of the critical force $\left(P_{k p, \ell}\right)^{*}$ for columns with different extent of penetration and different location of the crack and in cases when there are no registered cracks in reviewed columns $\left(P_{k p, o}\right)^{n n}$. For valuating the adequacy of the suggested mathematical model there have been determined the values of the critical force in columns with registered cracks using the analytical approach «The formulas of Euler $\left(P_{k p, o}\right)^{\text {Euler }}$ »- table 1. 
Each registered crack leads to reducing the critical force with different extent of effect that depends on the extent of penetration of the crack, the crack location and the imposed limitations in the border sections of the column. The comparative valuations for the extent of the effect of the mentioned factors are presented in a summary in table 2.

From the analysis of the summarized results for the critical force and the relative valuations of the modification of the critical force there has been established that the reviewed problem consists of many factors and the particular factors have an effect to a different extent upon the different combinations. Therefore that mutual relation between the different factors in the common functional dependency has a different power of effect. This fact demands entering a coefficient through which to report the complex effect of the reviewed factors. The entered coefficient is determined as a relation between the critical force for the reviewed column with registered cross crack with exactly identified location lengthwise of the column and exactly determined depth of penetration $\left(P_{k p, \ell}\right)^{x_{\ell}}$ and the respective value of the critical force for the reviewed column with registered crack in it, i.e.:

$$
\chi=\frac{\left(P_{k p, \ell}\right)^{x_{\ell}}}{P_{k p, o}}
$$

There has been assumed the description «critical coefficient of sensitiveness to the registered crack upon stability» and the results for it within the performed research are geometrically presented in figure 2. On the grounds of the analysis of the obtained results, the following conclusions are summarized:

- comparing the results for the critical force of a column with no registered crack that have been obtained by adaptation of the described algorithm in the programme product FRAME by SARS and these obtained by the formulas of Euler, the following relative valuations are determined: $\left(\square P_{k p, o}\right)^{c x .1}=0,17 \%$ и $\left(\square P_{k p, o}\right)^{c x .2}=0,28 \%$. This is a proof of the authenticity and the adequacy of the respective mathematical matrix model of a column with registered crack. Therefore the finite elements method is appropriate and effective method for the analysis of the stability of columns with registered cracks as a result of which it is fairly easy to define the values of the critical force;

- the value of the critical force for reviewed column with registered cross crack depends on the depth of penetration, the crack location lengthwise the column and the way of attachment of the border sections of the column. This is so because each registered crack leads to a modification of the local stiffness of the reviewed column;

- upon increasing the extent of penetration of the registered cross crack, the critical force of the reviewed column decreases as most significant are the modifications in the relative depth of penetration of the crack $\ell: h_{0}>0,2$. In these cases «the critical coefficient of sensitiveness to the registered crack upon stability" meets the condition 
$\chi_{k p}=\boldsymbol{P}_{k p, \ell}: \boldsymbol{P}_{k p, o}>0.950$ regardless of the way of attachment of the border sections of the column;

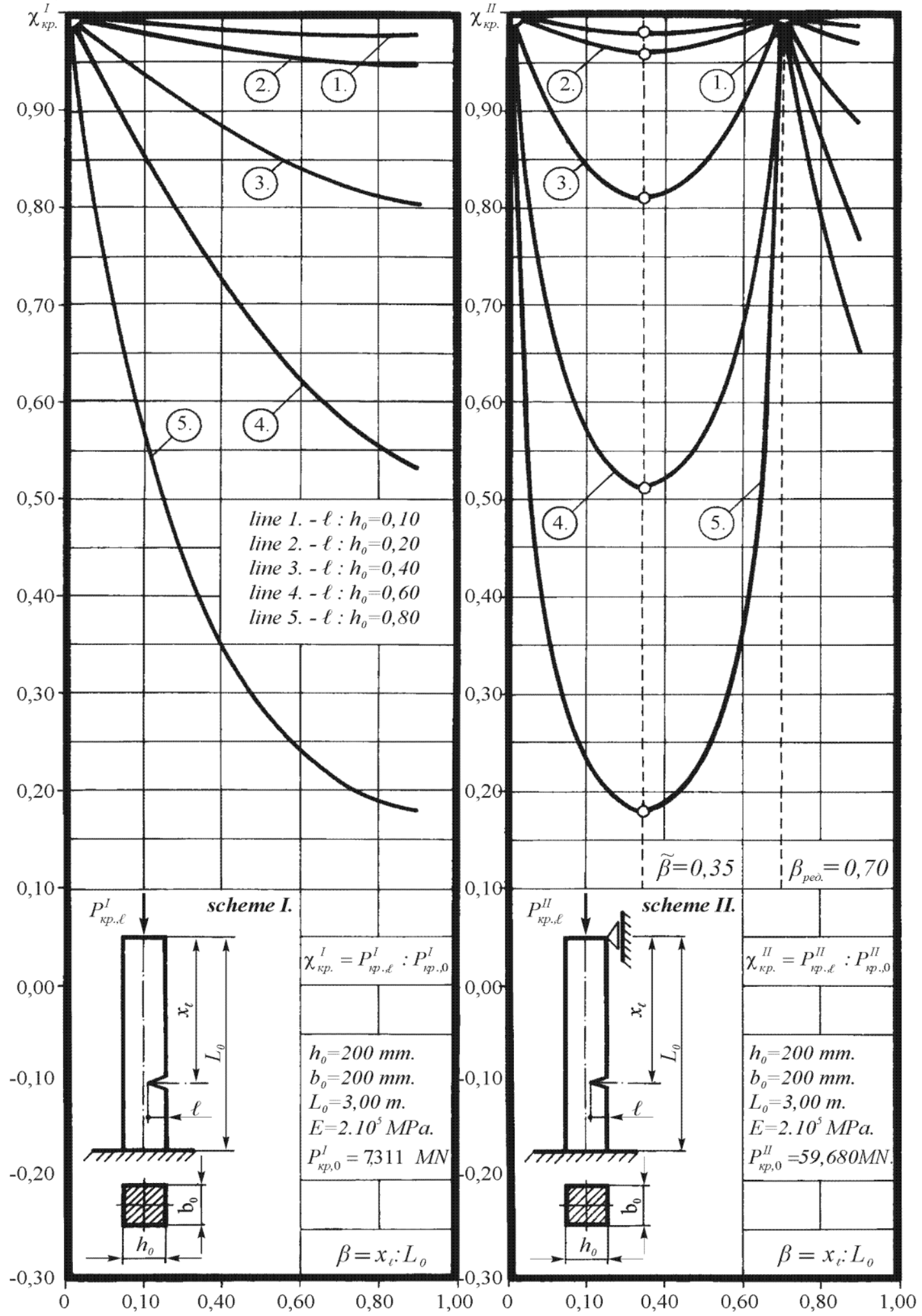


Fig. 2. Dependency of the coefficient of sensitiveness to the registered crack upon stability $X_{\kappa p .}$ from the crack location $x_{\ell}$, the extent of penetration of the crack $\ell$ and the scheme of attachment of the border sections of the reviewed slender column.

Table 1. Data for the critical force of the reviewed columns depending on the extent of penetration of the crack, the crack location and scheme of attachment of the border sections.

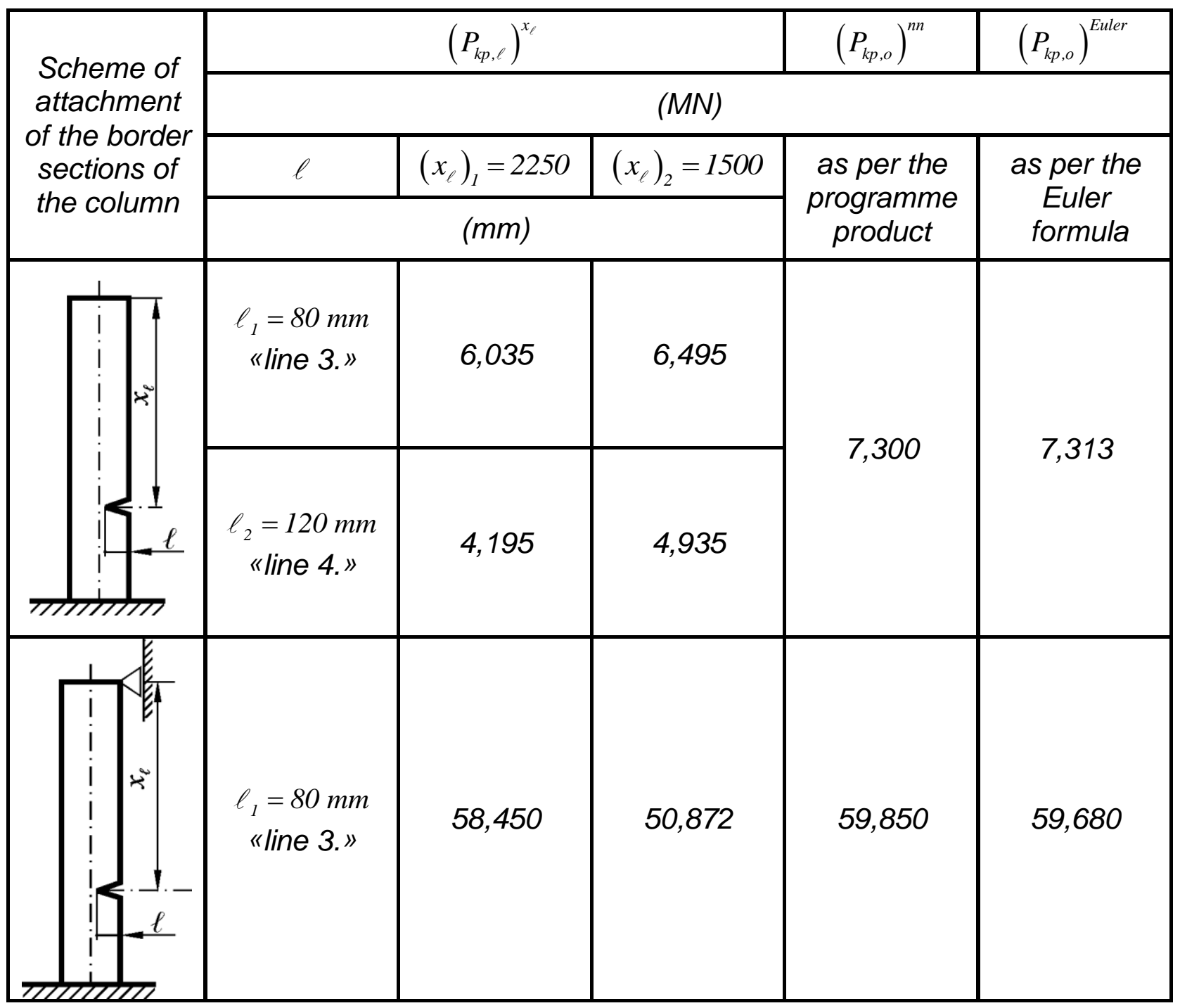

- the location of the registered crack has a different effect on the critical force depending on the way of attachment of the border sections of the column regardless of the depth of penetration of the column. Upon a console column, the greatest decrease of the critical force is when the crack is spreading in cross section near the attachment. Upon a console with blocked or jointly attached border sections when the crack is spreading in cross section with position coordinate $x_{\ell}=0,35$. $L_{0}$ towards the mobile cylindrical support, the greatest decrease of the critical force has been established upon the respective depth of penetration of the crack. On the other hand these are the cross sections of the columns for which the integral characteristic «bending moment» has a maximum value. Therefore if the plane of spreading of the registered crack coincides with the cross section of the 
column with maximum bending moment then this crack causes the greatest decrease of the critical force upon the respective depth of penetration. If the plane of registered crack spreading coincides with the inflexion cross sections of the column these are the sections in which the bending moments are equal to zero, «the critical coefficient of sensitiveness to the registered crack upon stability» is equal to one i.e. the critical force upon the respective depth of penetration is equal to the critical force for the reviewed column with no registered crack in it.

Table 2. The relative valuations of the modification of the critical force depending on the depth of penetration of the crack $\ell$, the crack location $x_{\ell}$ and the scheme of attachment of the borders sections of the column.

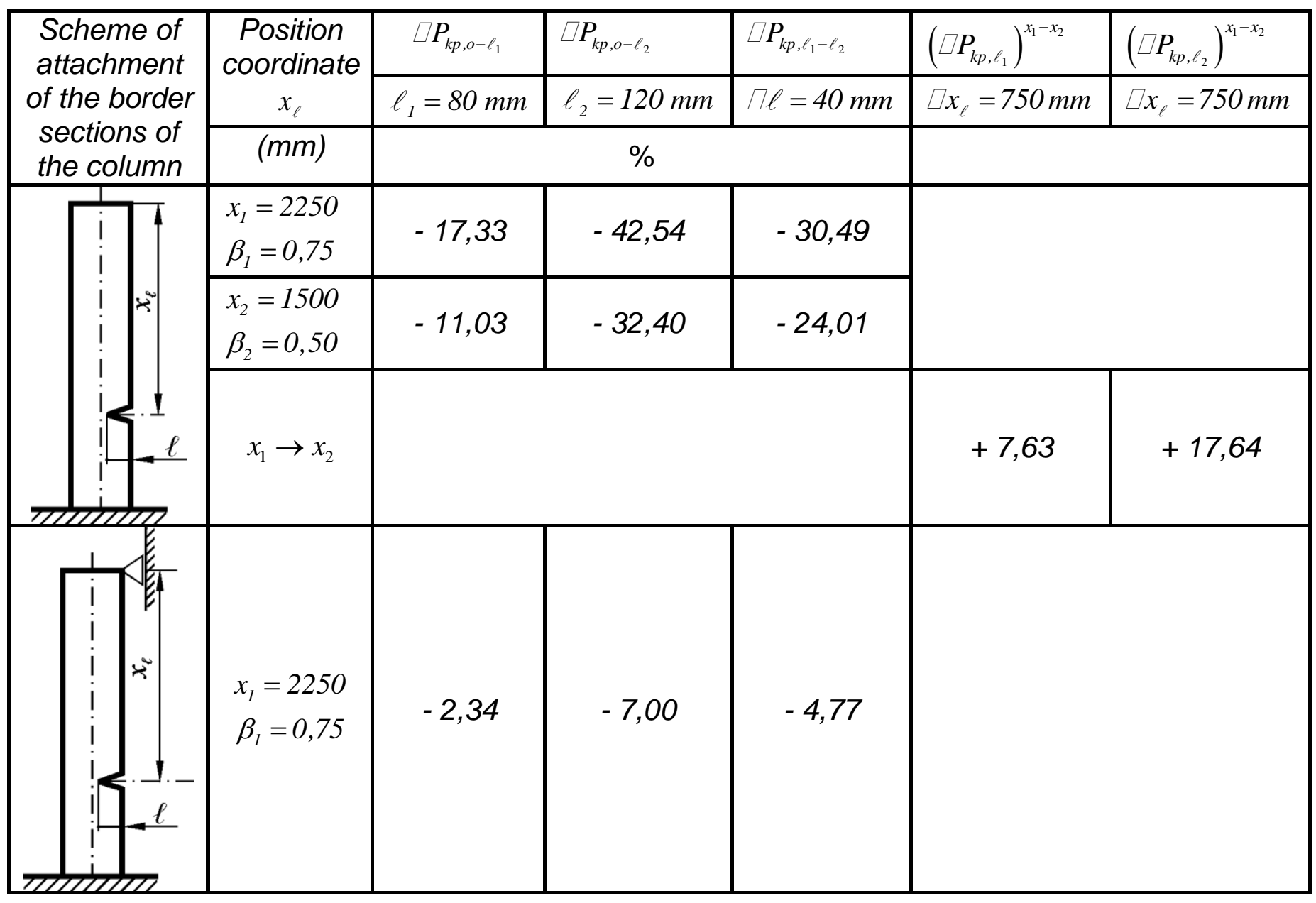

The research carried out in the present work refers to columns with one registered cross crack. Upon the presence of more registered cracks it is necessary to modify the developed programme that will be a subject of further research.

\section{Summary.}

The present work suggests a solution of a characteristical equation for determining the critical parameter through which the critical force for a column with a registered crack with particular 
depth of penetration, particular location lengthwise of the column and particular scheme of attachment of the border sections of the column is determined. For this purpose a synthesized computer finite-element model of the column has been prepared in the programme environment FRAME by SARS with one dimensional finite elements. There has been proved the effect of the extent of penetration of a registered cross crack on the value of the critical force upon different location of the plane for developing of the crack lengthwise of the column and upon different schemes of attachment of the border sections. There has been entered the "critical coefficient of sensitiveness to the registered crack upon stability" through which the complex effect of the location of crack lengthwise of the column, the extent of penetration of the registered crack and the attachment of the border sections are reported. There has been obtained new data of the critical force for a column with registered cross crack and for the "critical coefficient of sensitiveness to the registered crack upon stability" that show the areas of possible combinations of the monitored factors of impact. There has been established that the critical coefficient of sensitiveness to the registered crack upon stability and the modification of the critical force bear information regarding the number of registered cracks, the location of the registered crack and the extent of penetration of the crack upon a particular scheme of attachment of the border sections of the column that determines them as diagnostic parameters and it is preferably to these to find application upon developing new methods of diagnostics and non-destructive control.

\section{References}

[1] Abraham, O.N.L., Brandon, J.A. and Cohen, A.M., „Remark on the Determination of Compliance Coefficients at the Crack Section of a Uniform Beam with Circular Cross-Section", J. Sound Vib., 169(4), p. 570, $1994 .$.

[2] Bazant, Z.P. and Cedolin, L., „Stability of Structures: Elastic, Inelastic, Fracture and Damage Theories", Oxford University Press, New York, 1991.

[3] Bazant, Z. P., Chen, E.P., „Scaling of Structural Failure”, Applied Mechanics, Reviews ASME 50 (10), p. 593, 1997.

[4] Bilello, C. and Bergman, L.A., „Vibration of Damaged Beams Under a Moving Mass: Theory and Experimental Validation", J. Sound Vib., 274, p. 567,2004.

[5] Dimarogonas, A.D., „Modeling Damaged Structural Member For Vibration Analysis”, J. Sound Vib., 112, p. 541, 1987.

[6] Fan, S.C., and Zheng, D.Y., „Gibbs Phenomenon Free Fourier Series for Vibration and Stability of Complex Beams", American Institute of Aeronautics and Aeronautics Journal, 39 (10), p. 1977, 2001.

[7] Fan, S.C. and Zheng, D.Y., "Stability of a Cracked Timoshenko Beam-Column by Modified Fourier Series", J.Sound Vib., 264, p. 475, 2003.

[8] Gerard, G., and Becker, H., Handbook of Structural Stability, Column Research Committee of Japan, Corona, Tokyo, 1971.

[9] Khiem, N.T., and Lien, T.V., „A Simplified Method for Natural Frequency Analysis of a Multiple Cracked Beam", Journal of Sound and Vibration, 245 (4), p. 737, 2001.

[10] Kikidis, M.L. and Papadopoulos, C.A., „Slenderness Ratio Effect on Cracked Beam”, J.Sound Vib., 155(1), p.1, 1992.

[11] Kisa, M., and Brandon, J.A., "The Effects of Closure of Cracks on The Dynamics of A Cracked Cantilever Beam", Journal of Sound and Vibration, 238(1), p. 1-18, 2000.

[12] Kisa, M., ve Gurel, M.A., „Kusurlu Yapilarda Catlaktan Dolayi Meydana Gelen 
Direngenligin Bulunmasi ve Bilgisayar Programi”, Malzeme 2000 8. Denizli Malzeme Sempozyumu, p. 192-203, Denizli, 2000.

[13] Kisa, M., and Brandon, J.A., „Free Vibration Analysis of Multiple Open-edge Cracked Beams by Component Mode Synthesis", Structural Engineering and Mechanics, 10(1), p. 81-92, 2000.

[14] Kisa, M., „Free Vibration Analysis of a Cantilever Composite Beam with Multiple Cracks", Composites Science and Technology, 64(9), p. 1391-1402, 2004.

[15] Kishen, J.M.C. and Kumar, A., „Finite Element Analysis for Fracture Behavior of Cracked Beam-Columns", Finite Elem. Anal. Des., 40, p. 1773, 2004.

[16] Lee, H.P., „Fundamental Frequencies of Annular Plates with Internal Cracks”, Comput. \& Sruct., 43, p.1085, 1992.

[17] Li, Q.S., „Non-Conservative Stability of Multi-Step Non-Uniform Columns”, Int. J. Solids Struct., 39, p. 2387,2002.

[18] Li, Q.S., „Effect of Shear Deformation on the Critical Buckling of Multi-Step Bars”, Struct. Eng. Mech., 15(1), p. 71,2003.

[19] Ozen, M., Graduate Seminary, Miihendislikte Stabilite Problemi, Graduate School of Natural and Applied Sciences, Harran University, Sanliurfa, 2005.

[20] Papadopoulos, C.A., Dimarogonas, A.D., „Stability of Cracked rotors in The Coupled Vibration Mode", ASME J. Vib., Account, Stress Reability 111, p. 356, 1988.

[21] Papadopoulos, C.A. and Dimarogonas, A.D., „Coupled Vibration of Cracked Shafts”, J. Vib. Acoust., 114, p. 461,1992.

[22] Papadopoulos, C.A., "Some Comments on the Calculation of the Local Flexibility of Cracked Shafts", J. Sound Vib., 278, p. 1205. 2004..

[23] Shen, M.H.H., and Pierre, C, „Natural Modes of Bernoulli-Euler Beams with Symmetric Cracks", J. Sound Vib. 138, p. 115, 1990.

[24] Subrahmanyam, K.B. and Garg, A.K., „Uncoupled Flexural Vibrations of Straight Beams with All Possible Boundary Conditions Treated by a Transfer Matrix Method", J. Sound Vib., 204(3), p. 397, 1997.

[25] Ruotolo, R. and Surace, C, „Natural Frequencies of a Bar with Multiple Cracks”, J. Sound Vib., 272, p. 301,2004.

[26] Takahashi, I., „Vibration and Stability of a Cracked Shaft Simultaneously Subjected to a Follower Force with an Axial Force", Int. J. Solids Struct., 35(23), p. 3071, 1998.

[27] Takahashi, I., „Vibration and Stability of Non-Uniform Cracked Timoshenko Beam Subjected to Follower Force", Comput. Struct., 71, p. 585,1999.

[28] Timoshenko, S.P. and Gere, J.M., Theory of Elastic Stability, McGraw-Hill, New York, 1961.

[29] Zheng, D.Y., and Fan, S.C., „Natural Frequencies of a Non-uniform beam with Multiple Cracks via Modified Fourier Series", Journal of Sound and Vibration, 246 (2), p. 297, 2001.

[30] Zheng, D.Y., and Fan, S.C., „Natural Frequency Changes of a Cracked Timoshenko Beam by Modified Fourier Series", Journal of Sound and Vibration, 246 (2), p. 297, 2001.

[31] Zheng, D.Y. and Fan, S.C, „Vibration and Stability of Cracked Hollow-Sectional Beams", J. Sound Vib., 267, p. 933, 2003.

Contact us: 
Proceeding of the $14^{\text {th }}$ AMME Conference, 25 -27 May $2010 \quad$ Paper MD - 16

Varvara Georgieva Veselinova-Guteva - Assoc. Prof. PhD. Eng. - Vice Director 052/645 513; 0889/750 265 и 0894/642 313 